\title{
Ultrasonographically detected central venous catheter- related thrombosis in patient undergoing anticoagulation therapy during anesthetic induction
}

\author{
Hyo Jung Son ${ }^{1}$, Han Byeol Oh', Haesol Han', Jae-Won Baik', Eun-Ho Lee ${ }^{2}$ \\ ${ }^{1}$ Department of Anesthesiology and Pain Medicine, National Police Hospital, ${ }^{2}$ Department of Anesthesiology and Pain Medicine, Asan \\ Medical Center, Seoul, Korea
}

Received April 3, 2018

Revised May 10, 2018

Accepted May 11, 2018

Corresponding author

Eun-Ho Lee

Department of Anesthesiology and

Pain Medicine, Asan Medical Center,

88 Olympic-ro 43-gil, Songpa-gu,

Seoul 05505, Korea

Tel: +82-2-3010-3888

Fax: +82-2-470-1363

E-mail: leho@naver.com

ORCID:

https://orcid.org/0000-0002-6369-7429

\begin{abstract}
Catheter-related thrombosis (CRT) is a common complication of central venous catheter inserted into the internal jugular vein or subclavian vein. Most CRT is resolved with thrombolytic therapy without additional complications such as pulmonary embolism, deep vein thrombosis, or post-thrombotic syndrome. Unusually, we experienced asymptomatic CRT occurred in a patient undergoing anticoagulation therapy. Central venous catheter was inserted into the right subclavian vein and the patient received heparin therapy for treatment of myocardial infarction for 16 days before surgery. Thrombus was detected during ultrasonographic examination when placing additional central venous catheter with a SwanGanz catheter after induction of general anesthesia. The catheter with a thrombus was removed 5 hours after off pump coronary artery bypass surgery. Heparin therapy was started 24 hours after surgery and continued for three days owing to CRT. The patient received anticoagulation therapy including warfarin and aspirin consistently. He was discharged at 15 days after surgery.
\end{abstract}

Keywords: Anticoagulants; Central venous catheters; Thrombosis; Ultrasonography

\section{INTRODUCTION}

Catheter-related thrombosis (CRT) is the most common non-infectious complication that may arise from using central venous catheter (CVC). Its incidence varies widely ( $8 \%$ to $66 \%$ ) [1]. Most CRT is resolved with thrombolytic therapy without additional complications such as pulmonary embolism, deep vein thrombosis, or post-thrombotic syndrome [2]. Unusually, we experienced asymptomatic CRT that occurred in a patient undergoing anticoagulation therapy for managing myocardial ischemia. Here we describe a case of CRT from subclavian vein (SCV) catheter used before surgery. It was detected by ultrasonography during induction of general anesthesia.

\section{CASE}

A 69-year-old male patient was admitted to emergency room with sudden squeezing chest pain and cold sweating. He had a history of hypertension, diabetes mellitus, and acute myocardial ischemia treated with intravenous urokinase 25 years ago. His current medications included aspirin, clopidogrel, rosuvastatin, linagliptin, and gliclazide. Initial laboratory

This is an Open Access article distributed under the terms of the Creative Commons Attribution Non-Commercial License (http://creativecommons.org/licenses/by-nc/4.0) which permits unrestricted noncommercial use, distribution, and reproduction in any medium, provided the original work is properly cited. Copyright $@$ Medical Biological Science and Engineering. 
test showed creatine kinase-muscle/brain level of $21.0 \mathrm{ng} / \mathrm{mL}$ and troponin I $2.2 \mathrm{ng} / \mathrm{mL}$. Transthoracic echocardiography (TTE) demonstrated $24 \%$ of ejection fraction (EF) with multiple regional wall motion abnormality (RWMA) of left ventricle. Emergent coronary angiography confirmed 3 vessel diseases (total occlusion of middle portion of right coronary artery, distal portion of left circumflex coronary artery, and middle portion of left main coronary artery). He was sent to intensive care unit and CVC was inserted in the right SCV, and intravenous heparin was administered subsequently. On the fifth day of hospitalization, he showed unstable vital signs with pulmonary edema and fever. The patient was treated with antibiotics for pneumonia, but inotropic agent was not applied because of paroxysmal atrial fibrillation and ventricular tachycardia. Follow-up TTE was performed on the 11th day of hospitalization and it demonstrated $30 \%$ of EF with multiple RWMA. Thallium single-photon emission computed tomography (CT) showed partially reversible large sized severely decreased to absent perfusion in apical mid anterior, apical septal, apical lateral wall, and inferior wall and reversible large sized moderate to severely decreased perfusion in midbasal anterolateral and mid-basal inferolateral wall. Medical staff decided to perform coronary artery bypass surgery on the 16th day of hospitalization. Heparin was started from the first day of hospitalization with dose adjusted according to an activated partial thromboplastin time and was discontinued 10 hours before surgery.
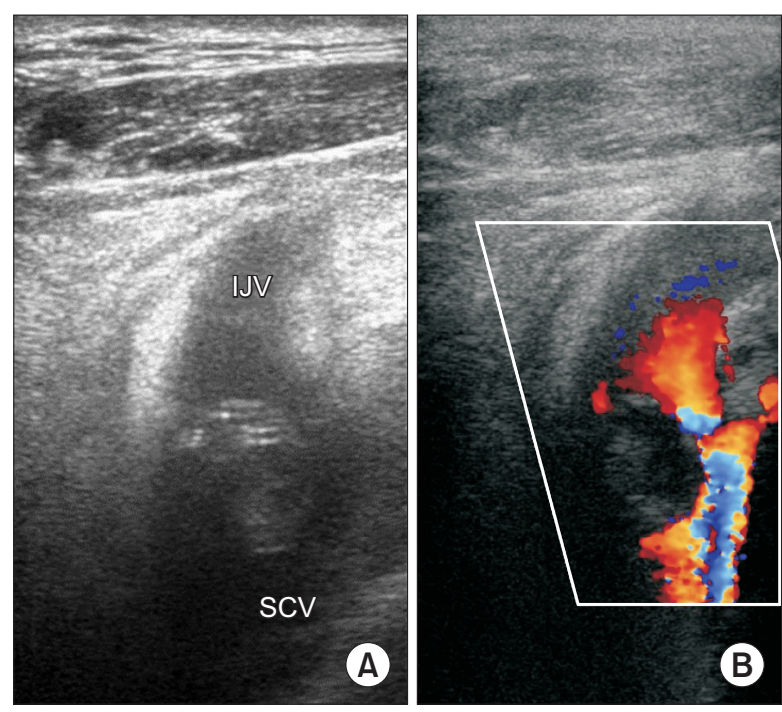

Fig. 1. Ultrasonographic images. (A) Echogenic mass on the junction of internal jugular vein (IJV) and subclavian vein (SCV). (B) Color doppler mode shows thrombosis that interferes with venous flow.
Prior to induction, a 5-lead electrograph, pulse oximeter, bispectral index monitor sensor, and cerebral oxymetry sensor were placed for monitoring. The patient had intra-arterial catheter in his radial artery and CVC in his right SCV. Anesthesia was induced with bolus doses of midazolam $5 \mathrm{mg}$ and rocuronium $100 \mathrm{mg}$ with continuous infusion of propofol (effect site concentration 1.0-2.0 $\mu \mathrm{g} / \mathrm{mL}$ ) and remifentanil (effect site concentration 9-16 $\mathrm{ng} / \mathrm{mL}$ ) using a target controlled infusion pump (Orchestra ${ }^{\circledR}$ Base Primea; Fresenius Vial, Brezins, France). After endotracheal intubation, we performed ultrasonographic examination to place additional CVC with a SwanGanz catheter on patient's right neck area. During procedure, $8 \mathrm{~mm}$ sized echogenic mass was detected surrounding the catheter that was placed 16 days ago (Fig. 1A). It was observed when a probe of ultrasonography was placed above supraclavicular notch and suspected to be CRT on junction of internal jugular vein (IJV) and SCV. Color doppler mode showed interruption of venous flow (Fig. 1B). Therefore, we performed central venous catheterization with a Swan-Ganz catheter on left IJV and reviewed results of pre-operative tests. We found defect of wall in junctional portion of right SCV and IJV in the 3-dimensional reconstruction image of thoraco-abdominal CT (Fig. 2), which was not mentioned in the test report. There were no adverse events during off pump coronary artery bypass surgery and catheter with a thrombus was removed 5 hours after the surgery. Heparin therapy was started 24 hours after surgery and was continued for three days owing to CRT.

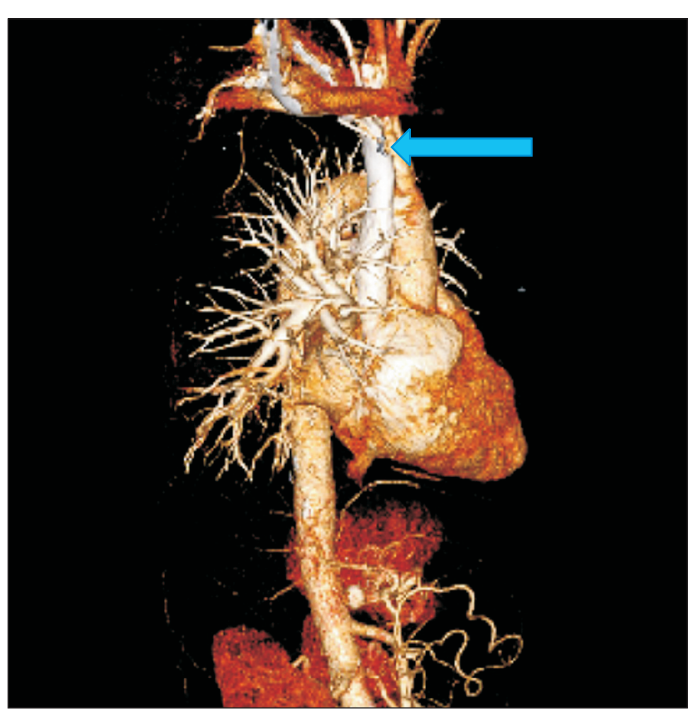

Fig. 2. Defect of image on the junction of right internal jugular vein and subclavian vein (arrow) in the 3-dimensional reconstruction image of thoraco-abdominal computed tomography. 
The patient received anticoagulation therapy including warfarin and aspirin consistently. He was discharged 15 days after surgery.

\section{DISCUSSION}

Central venous catheterization is essential and frequently inserted in patients requiring critical care. In case of surgery requiring massive volume administration or precise control of vital sign, anesthesiologist insert CVC mainly in IJV or SCV. Traditionally, anatomical landmarks have been used for CVC cannulation and CVC position has been confirmed through chest radiograph [3]. These days, portable ultrasonography is used for real-time procedural guidance for CVC insertion and veins can be cannulated under direct vision with confirmation of intraluminal position of catheter [4,5]. Examination using ultrasonography can also detect lesions such as anatomical abnormality of vein and thrombosis, and this has reduced complications.

However, CVC-related complications such as infection, occlusion, thrombosis, post-thrombotic syndrome, and pulmonary embolism are common. They are not only related to insertion, but also related to maintenance [6,7]. Among these complications, CRT is the most common complication except complications related to infection. Its incidence varies widely, ranging from $8 \%$ to $66 \%[1,8,9]$. Pathogenesis of CRT is multifactorial, but can be summarized as Virchow's triad: stasis, hypercoagulability, and endothelial injury [10]. CVC insertion can result vessel wall injury at the entry point of the catheter into the vein, thus activating coagulation and proinflammatory cascades. The velocity of blood flow is slow while maintaining the CVC in the vessel lumen, leading to stasis. In addition, synthetic materials used to construct CVC and infused drugs through the catheter that irritant the vessel wall might activate coagulation [11]. CRT most commonly occurs in upper extremities when catheters are kept for a long time [12]. Symptoms of CRT in upper extremities may include swelling, warmth, erythema, pain, tenderness to palpation, and development of collateral vessels in surrounding area []. In contrastly, most CRTs around CVC do not present clinical manifestations and are usually found by chance during ultrasonography examination. Although venography is the reference standard for diagnosis of CRT, ultrasonography is widely used as it is a noninvasive procedure. Ultrasonography shows direct visualization of thrombus and color doppler represents blood flow around thrombus [11].

CRT is usually resolved with anticoagulation therapy without additional embolic events [13]. However, because embolic events can be associated with high morbidity and mortality even though incidence is low, the American College of Chest Physicians and the International Clinical Practice Guidelines recommends antithrombotic therapy to manage CVC-related deep vein thrombosis $[14,15]$. The goal of CRT treatment is to relieve symptoms, preserve catheter function, minimize of thrombus progression, and prevent post-thrombosis syndrome. Treatment strategies include removal of CVC, anticoagulation, directed pharmacomechanical thrombolysis, and surgical thrombectomy. For patients with infection, persistent symptoms despite anticoagulation, and if the CVC is no longer needed, CVC removal should be considered. Anticoagulation for at least 3 months is recommended and thrombolysis should be considered only in patients who meet the following criteria: persistent severe symptoms, extent of thrombus from subclavian to axillary vein, symptoms $<14$ days, good performance status, life expectancy $\geq 1$ year, and low risk for bleeding [10].

In our case, CRT was detected incidentally during ultrasonographic evaluation of right IJV for additional CVC cannulation. Despite the patient was received heparin therapy for 16 days before surgery, thrombus occurred and interrupted blood flow both right IJV and SCV. If we did not evaluate right IJV and SCV by ultrasonography before CVC insertion, CRT might cause embolic events. As another CVC was inserted during anesthesia and the patient has been treated enough with heparin, the catheter with the thrombus was removed 5 hours after operation. Heparin therapy was started 24 hours after the surgery and continued for three days. It was then replaced by oral anticoagulants.

To reduce the incidence of thrombosis, the end of the catheter should be located in a brachiocephalic vein, or in the upper third of the SVC. And insertion of catheter should be performed carefully to minimize vascular injury [11]. In addition, the life span of the CVC should be kept as short as possible. Because the presence of CVC, even for a very short time, is associated with a high incidence of CRT, ultrasonography is needed before and after the use of CVC.

In conclusion, CRT is a common complication in patients with indwelling CVC and even occurs in patients with anticoagulation. Although the presence of CRT is likely to be benign 
with low risk of embolic complications in the absence of patent foramen ovale or intracardiac shunts, anesthesiologists should be alert and consider the possibility of CRT in CVC used before surgery, even if it works normally.

\section{CONFLICT OF INTEREST}

No potential conflict of interest relevant to this article was reported.

\section{REFERENCES}

1. Baskin JL, Pui CH, Reiss U, Wilimas JA, Metzger ML, Ribeiro RC, et al. Management of occlusion and thrombosis associated with long-term indwelling central venous catheters. Lancet 2009;374:159-69.

2. Verso M, Agnelli G. Venous thromboembolism associated with long-term use of central venous catheters in cancer patients. J Clin Oncol 2003;21:3665-75.

3. Fletcher SJ, Bodenham AR. Safe placement of central venous catheters: where should the tip of the catheter lie? $\mathrm{Br} J$ Anaesth 2000;85:188-91.

4. Leung J, Duffy M, Finckh A. Real-time ultrasonographicallyguided internal jugular vein catheterization in the emergency department increases success rates and reduces complications: a randomized, prospective study. Ann Emerg Med 2006;48:5407 .

5. Miller AH, Roth BA, Mills TJ, Woody JR, Longmoor CE, Foster B. Ultrasound guidance versus the landmark technique for the placement of central venous catheters in the emergency department. Acad Emerg Med 2002;9:800-5.

6. McGee DC, Gould MK. Preventing complications of central ve- nous catheterization. N Engl J Med 2003;348:1123-33.

7. Ruesch S, Walder B, Tramèr MR. Complications of central venous catheters: internal jugular versus subclavian access--a systematic review. Crit Care Med 2002;30:454-60.

8. Boersma RS, Jie KS, Verbon A, van Pampus EC, Schouten HC. Thrombotic and infectious complications of central venous catheters in patients with hematological malignancies. Ann Oncol 2008;19:433-42.

9. McCloskey DJ. Catheter-related thrombosis in pediatrics. Pediatr Nurs 2002;28:97-102, 105-6.

10. Rajasekhar A, Streiff MB. How I treat central venous access device-related upper extremity deep vein thrombosis. Blood 2017;129:2727-36.

11. Fabiani A, Pittiruti M, Russo S, Sanson G. Early-onset thrombosis of internal jugular vein associated with introducer catheter for heart catheterization in cardiac surgery. J Vasc Access 2015;16:57-63.

12. Joffe HV, Kucher N, Tapson VF, Goldhaber SZ; Deep Vein Thrombosis (DVT) FREE Steering Committee. Upper-extremity deep vein thrombosis: a prospective registry of 592 patients. Circulation 2004;110:1605-11.

13. Chick JF, Reddy SN, Bhatt RD, Shin BJ, Kirkpatrick JN, Trerotola SO. Significance of echocardiographically detected central venous catheter tip-associated thrombi. J Vasc Interv Radiol 2016;27:1872-7.

14. Debourdeau P, Farge D, Beckers M, Baglin C, Bauersachs RM, Brenner B, et al. International clinical practice guidelines for the treatment and prophylaxis of thrombosis associated with central venous catheters in patients with cancer. J Thromb Haemost 2013;11:71-80.

15. Kearon C, Akl EA, Ornelas J, Blaivas A, Jimenez D, Bounameaux $\mathrm{H}$, et al. Antithrombotic therapy for VTE disease: CHEST guideline and expert panel report. Chest 2016;149:315-52. 